\title{
Extra-spinal sciatica and sciatica mimics: a scoping review
}

\author{
Md Abu Bakar Siddiq ${ }^{1,2}$, Danny Clegg ${ }^{3}$, Suzon Al Hasan ${ }^{4}$, and Johannes J Rasker ${ }^{5}$ \\ 'Physical Medicine and Rehabilitation Department, Brahmanbaria Medical College, Brahmanbaria, Bangladesh \\ ${ }^{2}$ School of Health Sport and Professional Practice, University of South Wales, Pontypridd, United Kingdom \\ ${ }^{3}$ School of Health and Social Care, London South Bank University, London, United Kingdom \\ ${ }^{4}$ Physical Medicine and Rehabilitation Department, Rajshahai Medical College, Rajshahai, Bangladesh \\ ${ }^{5}$ Faculty of Behavioral Management and Social Sciences, Psychology Health and Technology, University of Twente, Enschede, The Netherlands
}

Received June 23, 2020

Revised July 30, 2020

Accepted August 3, 2020

Handling Editor: Kyung Hoon Kim

Correspondence

Md Abu Bakar Siddiq

Physical Medicine and Rehabilitation

Department, Brahmanbaria Medical

College, Ghatura, Brahmanbaria Sadar,

Brahmanbaria 3400, Bangladesh

Tel: +8801718133427

Fax: +01733-382345

E-mail: abusiddiq37@yahoo.com
Not all sciatica-like manifestations are of lumbar spine origin. Some of them are caused at points along the extra-spinal course of the sciatic nerve, making diagnosis difficult for the treating physician and delaying adequate treatment. While evaluating a patient with sciatica, straightforward diagnostic conclusions are impossible without first excluding sciatica mimics. Examples of benign extra-spinal sciatica are: piriformis syndrome, walletosis, quadratus lumborum myofascial pain syndrome, cluneal nerve disorder, and osteitis condensans ilii. In some cases, extra-spinal sciatica may have a catastrophic course when the sciatic nerve is involved in cyclical sciatica, or the piriformis muscle in piriformis pyomyositis. In addition to cases of sciatica with clear spinal or extra-spinal origin, some cases can be a product of both origins; the same could be true for pseudo-sciatica or sciatica mimics, we simply don't know how prevalent extra-spinal sciatica is among total sciatica cases. As treatment regimens differ for spinal, extra-spinal sciatica, and sciatica-mimics, their precise diagnosis will help physicians to make a targeted treatment plan. As published works regarding extra-spinal sciatica and sciatica mimics include only a few case reports and case series, and systematic reviews addressing them are hardly feasible at this stage, a scoping review in the field can be an eye-opener for the scientific community to do larger-scale prospective research.

Key Words: Buttocks; Chronic Pain; Low Back Pain; Lumbar Vertebrae; Myofascial Pain Syndrome; Osteitis; Piriformis Muscle Syndrome; Sciatica; Sciatic Nerve.

\section{INTRODUCTION}

The ancient Greeks used the term 'sciatica' or ischias (Greek i $\sigma \chi \imath \alpha_{\zeta}$ ) to describe pain around the hip or thigh [1]. In the nineteenth century, disc disorders were first recognized, and in 1864 Lasègue described a test that was provocative for sciatica pain, later named after him. In 1934, Mixter and Barr [2] concluded that a prolapsed, intervertebral disc (IVD), compressing adjacent sciatic nerve (SN) roots, produced sciatica features, based on excised 'chondromas' of the spine, which were on display in the Harvard medical school pathology museum. The presence of pain was initially, and often still is, ascribed to pressure on nerve roots. In 1956, Kelly believed that pressure on a nerve would lead to loss of function and not to pain. Later, Lindahl and Rexed (1996) reported findings from laminectomy, proving that the inflammatory response of injured nerve roots caused by prolapsed lumbar intervertebral disc (PLID), led to development of sciatica-type pain [1].

Lumbago means low back pain (LBP), and mostly exists (c) This is an open-access article distributed under the terms of the Creative Commons Attribution Non-Commercial License (http://creativecommons.org/licenses/by-nc/4.0/), which permits unrestricted non-commercial use, distribution, and reproduction in any medium, provided the original work is properly cited.

(C) The Korean Pain Society, 2020
Author contributions: Md Abu Bakar Siddiq: Writing/manuscript preparation; Danny Clegg: Writing/manuscript preparation; Suzon Al Hasan: Writing/manuscript preparation; Johannes J Rasker: Writing/manuscript preparation. 
without SN involvement $[3,4]$. However, patients who experience LBP which radiates to the leg(s) report clinically worse symptoms and poorer recovery than those with LBP alone $[3,4]$. Sciatica means any pain transmitted along the SN roots and SN course, and leads to different levels of impairment, especially in elderly people, as well as socioeconomic consequences because of loss of working hours, and difficulty in the approach to treatment [4]. Sciatica due to slipped disc often starts suddenly with lifting, and the pain gets worse when coughing, sneezing, pressing, and sitting while experiencing jolting movements. Physical examination reveals a positive Lasègue with or without neurological deficits - motor, sensory and/or both $[3,4]$. In about $90 \%$ of the patients, sciatica is caused by a spinal disc herniation pressing on one of the lumbar or sacral nerve roots, with a life-time incidence ranging between 13 to $40 \%[1,5]$. Besides, spondylolisthesis, lumbar spondylosis with osteophytic lipping, spinal canal stenosis, piriformis syndrome (PS), pelvic tumors, and pregnancy are other possible causes of sciatica [1].

Compression of the SN outside the spine (pelvic or extra-pelvic) also may generate sciatica-like symptoms [3]. Pathologies from the sacroiliac (SI) and hip joints with referred pain to the back does not only confuse treating physicians, but also create a diagnostic challenge, a phenomenon termed "the hip-spine dilemma". Outside of the spine, the SN may become compressed at points along its course, irrespective of age, sex, and occupation [6,7]. In our recent study, an example of extra-spinal sciatica, namely PS, was seen almost with equal frequency both in men and women, being slightly more common in housewives [7]. Sciatica also is reported as emerging from pathology in the vicinity of the inferior gemellus muscle, such as hip adductor muscle tear(s), wallet neuritis, ossified bone tissue (hip/femur), piriformis pyomyositis, SN endometriosis, SN tumor, malignant invasion to $\mathrm{SN}$, and cluneal nerve disorder [8-12]. Amongst others, osteitis condensans ilii (OCI), inflammatory sacroiliitis, referred pain from the quadratus lumborum (QL) muscle, myofascial pain syndrome, meralgia paraesthetica, gluteal medius (GME) tendinitis, post-injectional gluteal neuropathy, also mimic sciatica $[7,13,14]$. But we do not yet know the answer to the question; how prevalent is extra-spinal sciatica among all sciatica? As well as, which one is more prevalent, spinal or extra-spinal?

Lumbar sciatica, extra-spinal sciatica, and sciatica mimics, all can be treated with pharmacological non-steroidal anti-inflammatory drugs (NSAIDs), analgesics, adjuvant analgesics, and non-pharmacological approaches including: transcutaneous electrical nerve stimulation, diseasespecific therapeutic exercises, cognitive behavioral therapy, and modification of the activities of daily living. When these appear ineffective, target-specific interventions (depending on the structure involved) may help [7,12,14]. Many studies have been conducted regarding sciatica due to lesions in the lumbar spine, however, there are scarce publications on extra-spinal sciatica, and its prevalence is in all likelihood underestimated [4].

Thus, before planning an intervention in a patient with sciatica, it is of paramount importance to differentiate spinal sciatica from extra-spinal sciatica, sciatica mimics, and/or whether it is a case of LBP arising in/around structures along the route followed by a dermatome, which could be confused with radiating pain specifically originating in the SN. For example, a patient with a herniated disc causing nerve root compression may experience pain along the partial/full dermatome in a SN pattern. If this patient also had a secondary injury in one of the extraspinal areas, and/or the extra-spinal pathology has led to the SN being vulnerable to secondary injury, then we must consider the "double-crush" sciatica presentation also.

We were unable to find evidence-based, updated systematic reviews, systematic search and reviews, or a metaanalysis regarding extra-spinal sciatica or sciatica mimickers, indicating the scope for drafting a scoping review. In the present article, we focus on diagnostic and therapeutic approaches to extra-spinal sciatica, and sciatica mimickers, in order to create updated information, readily available for treating physicians.

\section{MAIN BODY}

\section{Literature review}

Using the PubMed and PubMed Central databases, articles describing extra-spinal sciatica and sciatica mimics were searched and included in the review. For each search, the following keywords were used: 'piriformis syndrome', 'wallet neuritis', 'piriformis pyomyositis', 'osteitis condensans ilii', 'superior cluneal nerve disorder', 'cyclical sciatica', 'post-injection sciatica', and 'extra-pelvic compressive neuropathy'. As it is a scoping review, there were no strict exclusion and inclusion criteria to follow. However, articles which fell into any of the following categories were excluded from this new synthesis: 1) those not in the English language, and 2) those not related to extra-spinal sciatica or sciatica mimics. No exclusion was applied based on publication dates, however, considerable emphasis was focused on the most relevant and up-to-date information available at the time of this review.

Reviewed articles included in the paper are 1) case reports (including one cadaveric report), 2) case series, 3) narrative and literature reviews, 4) longitudinal cohorts, 5) 


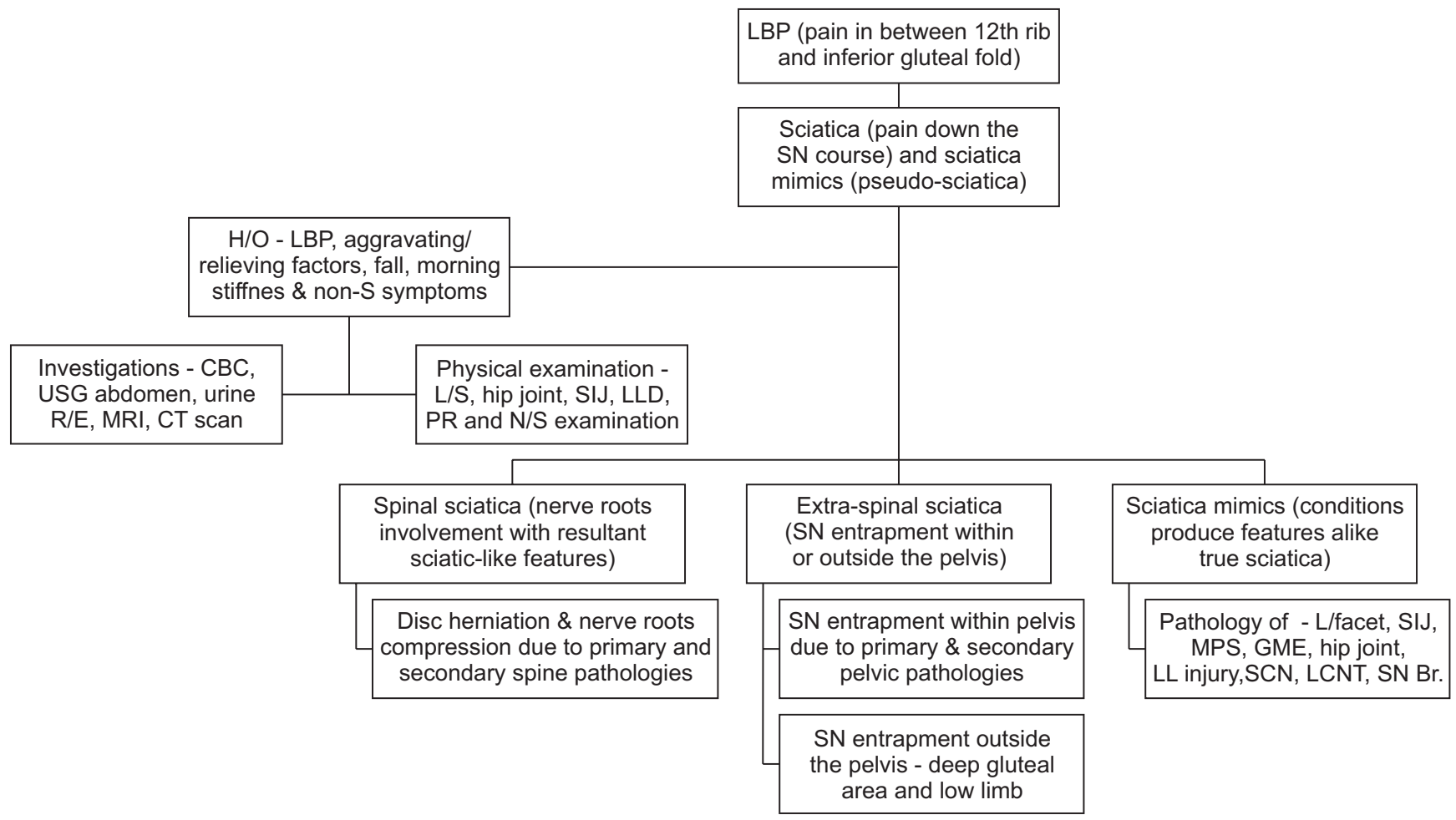

Fig. 1. Schematic diagram of how to approach sciatica and sciatica mimics. LBP: low back pain, SN: sciatic nerve, H/O: history of, non-S: non specific symptoms, CBC: complete blood count, USG: ultrasonogram, R/E: routine examination, MRI: magnetic resonance imaging, CT: computed tomography, L/ S: lumbar spine, SIJ: sacroiliac joint, LLD: leg length discrepancy, PR: per-rectal, N/S: nervous system, L/facet: lumbar facet, MPS: myofascial pain syndrome, GME: gluteus medius, LL: lumbar ligament, SCN: superior cluneal nerve, LCNT: lateral cutaneous nerve of thigh, SN Br.: SN branch.

cross-sectional studies, 6) expert opinions/letters to editor, 7) systematic reviews and meta-analyses, 8) clinical trials randomized controlled trials (RCT), and non-RCT, 9) casecontrol studies, 10) conference proceedings, and 11) preclinical studies. Selected articles were checked for Critical Appraisal Skills by using the Program (CASP) checklist [15]. The schematic diagram presents how to approach for diagnosis of extra-spinal sciatica and sciatica mimics (Fig. 1). Table 1 demonstrates different extra-spinal sciatica and sciatica mimickers.

\section{Extraspinal sciatica and sciatica mimickers}

\section{1) PS}

Mixter and Barr [2] explored the correlation between clinical and pathological features of nerve root compression in herniated IVD. Extra-spinal compression of the nerve trunk under the piriformis muscle (PM) was proposed by Freiberg and Vinke, however, Robinson first coined the PS term in relation to sciatica: a compressive sciatic neuropathy resulting from the PM vicinity [15-17]. The estimated prevalence of PS ranged between $6 \%$ and $36 \%$, and being more prevalent in females than males, because of altered pelvic biomechanics and a wider Q-angle $[7,18]$.
PS may develop in people with all kind of occupations, but appeared more frequently among housewives $[7,18]$. PS is prevalent during the fourth and fifth decades of life, but can be seen in both sexes irrespective of age [7].

Clinical features of PS are inconsistent, and this explains why it often not diagnosed, or only diagnosed in the very late stages of sciatica treatment [18]. Features of PS may sometimes be indistinguishable from that of sciatica caused in the lumbar spine, a reason why PS is sometimes over-diagnosed [18]. There are two types of PS: primary (PM spasm due to myofascial pain syndrome), and secondary, due to leg-length discrepancy, fibromyalgia, spinal stenosis, or congenital variation of either the PM and/ or SN $[19,20]$. Though there is no strict diagnostic criteria for the disorder at the time of this review, in a systematic review by Hopayian and colleagues [16], they reported the following features which are most consistently found: 1) buttock pain, 2) external tenderness over the greater sciatic notch, 3) aggravation of the pain through sitting, and 4) augmentation of the pain with maneuvers that increase PM tension.

Recently we described PS among the Bangladeshi people as, 'localized and or radiating gluteal pain that is aggravated by sitting on the affected side, lying down, rising from sitting to standing position, and incorrect squatting 


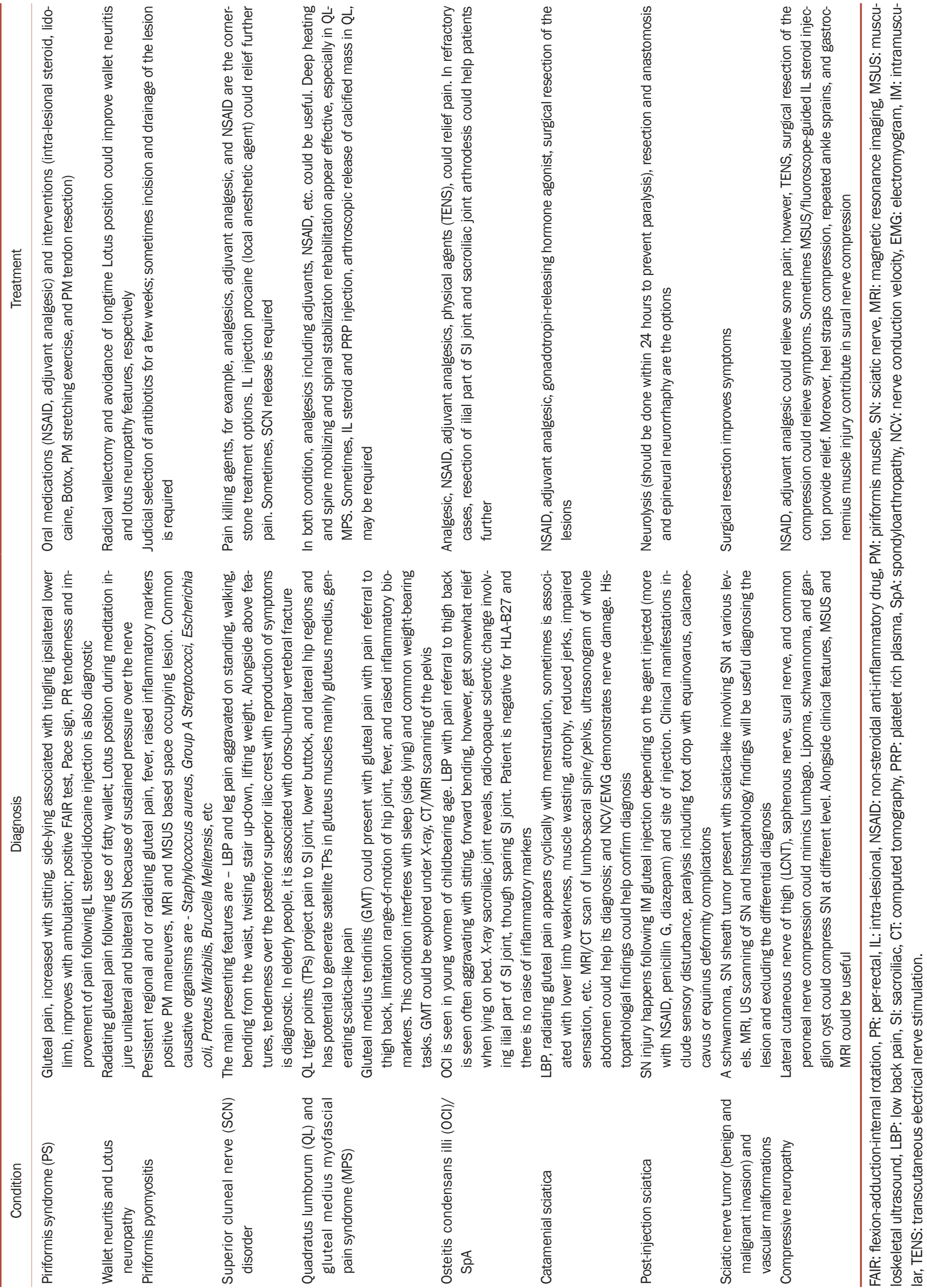



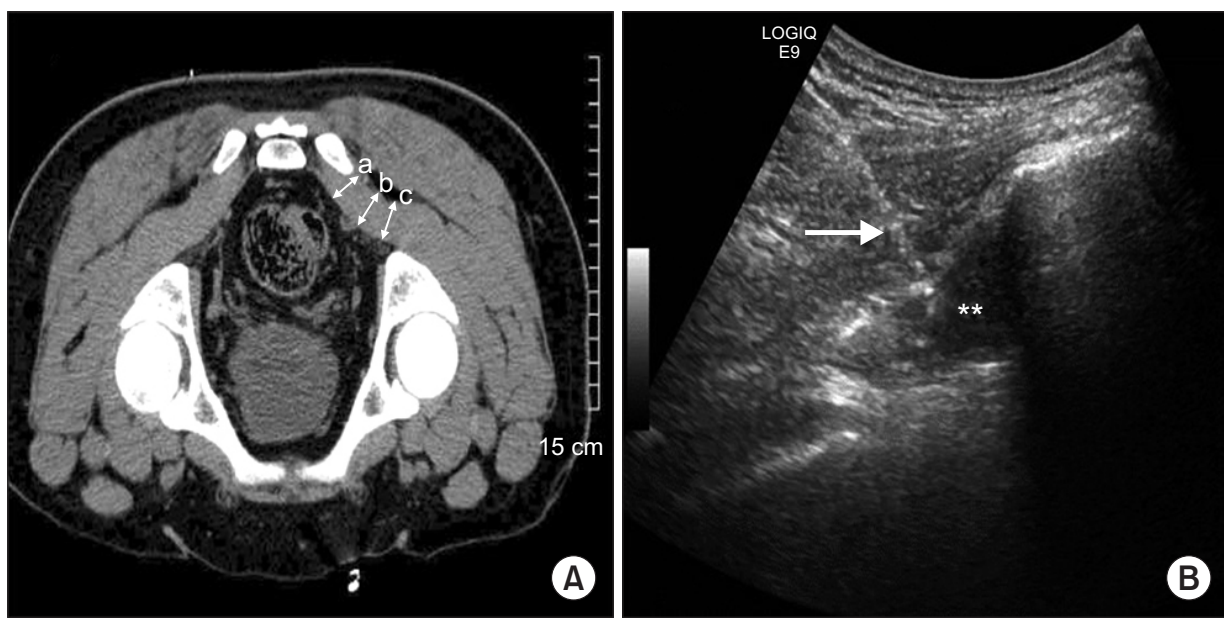

Fig. 2. Imaging of piriformis muscle (PM). (A) Computed tomography based PM diameter measurement. (a), (b), and (c) represent the diameters of PM. (B) Ultrasonogram guided PM injection. Asterisks and arrow indicate hypoechoic PM and hyperechoic spinal needle trajectory, respectively. Adapted from the article of Park et al. (Korean J Pain 2011; 24: 87 92) [21] and Jeong et al. (Ultrasonography 2015; 34: 206-10) [23].

technique, though slightly improved with ambulation, and improving with intra-lesional (IL) corticosteroidlidocaine injection' $[7,20]$. Likewise, external tenderness on deep palpation over the greater sciatic notch, internal pelvic tenderness via vagina or rectum examination, positive Freiberg's test, Pace sign, Flexion-Adduction-Internal Rotation (FAIR) test, and the Beatty test, are useful for PS diagnosis [16].

However, there are PS mimics, and some of them, in fact, originate from the lumbosacral spine, hence further exploration under radio-imaging is required to exclude them, and confirm PS diagnosis. There is no diagnostic radio-imaging gold standard for PS, but magnetic resonance imaging (MRI)/ computed tomography (CT) scanning of the pelvis-lumbosacral spine and high-frequency gluteal ultrasonography can be successful in delineating PM pathology (Fig. 2A) [21]. Fishman et al. [22] demonstrated a delay in the H-reflex on the electromyogram (EMG) in the FAIR position, and this may be useful in PS diagnosis. The FAIR test, coupled with IL injection, can be both diagnostic and therapeutic in PS [22]. MR neurography can reveal PM asymmetry and SN hyper-intensity at the greater sciatic notch with a specificity and sensitivity of $93 \%$ and $64 \%$, respectively.

Oral medications including NSAIDs, adjuvant analgesics (antidepressants and anticonvulsants), muscle relaxants, and PM stretching exercise are frequently used to treat the disorder and have been found somewhat effective. Also, musculoskeletal ultrasound (MSUS), fluoroscopyguided IL corticosteroid, and botulinum injections have been found useful (Fig. 2B) [23]. The surgical resection of PM tendon sometimes may be required in refractory cases $[23,24]$. In secondary PS, identifying and treating of the primary cause is also important.

\section{2) Wallet neuritis}

Wallet neuritis, "walletosis", "fat-wallet syndrome", and "credit-carditis" are sometimes used interchangeably to describe PS [18]. In 1966, the term "credit-carditis" was used for the first time, and was suggested to describe gluteal pain with sciatic neuritis from an overloaded wallet [25]. It is assumed that a loaded wallet led to altered alignment of the lumbo-sacral spinal segments, pelvis, and deep gluteal structures, with resultant PS features. So, when evaluating walletosis, we must assess whether the $\mathrm{PM}$ is involved, and without screening this, use of PS nomenclature interchangeably with wallet neuritis appears to be something of a misnomer [26]. Persistent pressure from a wallet may even cause demyelination of the SN, as shown on the EMG in a patient with deep gluteal pain, while negative for: FAIR test, piriformis sign, Freiberg's test, Pace sign, and digital per-rectal examination (while the finger glides over the spasmodic PM) [14]. Alongside these clinical maneuvers, pelvis CT/MRI scanning, MRI neurography, and MSUS, favoring PS diagnosis, may be uneventful in walletosis $[14,16]$.

Developing wallet neuritis features may take a longtime, and unlike PS patients, sufferers rarely visit a medical emergency facility. But both conditions could coexist in the same individual, as revealed in our previous research, a form of double crush [7,14]. The number of patients with wallet-related neuritis is rising alarmingly world-wide, for example, millions of Americans are experiencing this problem, which needs to be more strategically investigated and solved [26]. We don't yet know whether there is any link between gluteal contour, wallet size and wallet quality. However, Lutz first mentioned even a 28 $\mathrm{mm} \times 37 \mathrm{~mm}$-sized wallet could generate features of wallet neuritis [27]. Acetaminophen, NSAIDs, and adjacent analgesics could give some relief. However radical "wallectomy" is the most appropriate intervention for wallet 
neuritis [14].

\section{3) Lotus neuropathy}

Isolated sciatic neuropathy is reported following performing the lotus position in yoga, a posture where the feet are tightly tucked under the thighs and buttocks for hours at a time [28]. Patients could complain gluteal pain, weakness and atrophy of lower limb muscle, and foot drop [28]. The modified lotus meditation position could result in severe SN neuropathy, as evidenced by the EMG of a patient who has no abnormal findings in lumbar MRI [28]. Bilateral compressive extra-pelvis EMG-evidenced SN injury has also been demonstrated in a 60 -year-old alcohol-intoxicated Korean woman, who fell asleep in the lotus posture for 10 hours. Improvement with conservative treatment is documented. However, recovery may be complicated by Achilles tendon contracture, pes planus, and foot drop $[28,29]$.

\section{4) Piriformis pyomyositis}

Piriformis pyomyositis, a purulent PM condition, may involve both juvenile and adult cases. In our recent systematic search and review, Staphylococcus aureus appears to be the most frequent causal microorganism. However, Group A Streptococci, Escherichia coli, Proteus Mirabilis, and Brucella Melitensis may also contribute to the pathology [30]. Clinical manifestations in piriformis pyomyositis are the same as in PS, however, persistent aggressive gluteal pain with fever, raised inflammatory biomarkers, CT guided aspiration culture reports, and characteristic findings on MRI and/or CT scanning of the deep-seated PM, favor a piriformis pyomyositis diagnosis [30].

Oral NSAIDs and antibiotics, according to the blood and drainage aspirate culture reports, are sometimes effective. When antibiotics fail, surgical drainage is warranted. IL corticosteroid injection should be avoided in piriformis pyomyositis $[20,30]$.

\section{5) Cyclical sciatica or catamenial sciatica}

In cyclical sciatica, women complain of sciatica-like pain (leg pain and weakness) during menstruation (catamenial) caused by engorgement of deposited ectopic endometrial tissue in and around SN, followed by symptom-free intervals between menstrual cycles [31,32]. The right SN is involved in two-thirds of cases, however, the left-side may also be involved [31]. Severe LBP with voiding difficulty, due to intra-medullary deposition of endometrial tissue adjacent to the conus medullaris and around pudendal and obturator nerve, may mimic sciatica of lumbar spine origin [33,34].

Among several hypotheses describing catamenial sciatica, coelomic metaplasia and hematogenic spread may explain the association of cyclical sciatica with endometriosis. However, the 'pocket sign' theory (exvagination of the peritoneum into the retro-peritoneal tissue towards the SN) has become the most popular explanation for catamenial sciatica $[35,36]$. Possover and colleagues first proposed a neural hypothesis describing the role of the pelvic nervous system in endometriosis [37]. Later, Siquara De Sousa et al. [38] described that endometriotic cells and stroma, propelling from deep adenomyotic nodules along the fine uterine nerves toward the inferior hypogastric plexus, and into the utero-sacral ligament, could cause pain due to neurogenesis and angiogenesis.

Besides clinical features, radio-imaging by MRI/CT scan of the lumbo-sacral spine/pelvis, ultrasonogram of the whole abdomen may be useful for differential diagnosis $[39,40]$. Where MRI pelvis and lumbar scanning appear negative for SN endometriosis, MRI screening of the ipsilateral hip/thigh may delineate extra-pelvic SN endometriosis. Using MRI, a catamenial mass lesion can be differentiated from a benign sciatic neuroma. Nerve conduction velocity and EMG demonstrate signs of denervation and resultant muscle change, respectively $[39,40]$. However, only the histopathology of ectopic endometriosis can confirm the diagnosis and exclude malignancy [39]. Immunohistochemical staining also reveals positivity for estrogen receptors in epithelial and stromal cells [39].

On physical examination, impaired sensory function and muscle power, as well as lower extremity jerks, may be found $[39,40]$. Moreover, demonstration of a regressing lesion during hormonal therapy may also help in diagnosis. Endometriosis treatment includes pain control, gonadotropin-releasing hormone antagonist, and surgical resection of the lesions [40]. If endometriosis of the $\mathrm{SN}$ is not treated early, fibrosis will result [31]. Unfortunately, some women are wrongly diagnosed as having lumbago sciati$\mathrm{ca}$, and thus treated with instrumented fusion of lumbar spine segments and/or lumbar laminectomy, predisposing the patients for developing long-term disabilities. So, before intervening, differentiation between catamenial sciatica and lumbar spinal sciatica is crucial, especially in a woman of reproductive age.

\section{6) $\mathrm{OCI}$ and axial spondyloarthropathy (SpA)}

OCI is an example of a cause of axial LBP, common in young women of childbearing age, with a reported prevalence of 0.9 to $2.5 \%$ [41]. However, the condition can also be seen among nulliparous women, and in men [42]. In this disorder, the ilial part at the distal third of the SI joint is 
involved, sparing the sacrum and SI joint space [41]. In an earlier study, Gillespie and Lloyd-Roberts [43] documented 2.2\% OCI after examining 760 lumbosacral spines.

Patients usually complain of LBP which is aggravated during both activity and inactivity, and without significant morning stiffness, as seen in SpA; the pain may also refer down to the back of the thigh and the posterior-medial aspect of leg $[43,44]$. OCI could be both unilateral and bilateral. There are no universally-agreed diagnostic criteria set for OCI, albeit the following features could be used as a diagnostic tool [41] : 1) unilateral or bilateral radiographic sclerosis of the lower part of the iliac bone of the corresponding SI joint, 2) female sex, 3) normal inflammatory parameters, 4) negative for HLA-B27 antigen, 5) normal bone scan, and 6) no bone erosions [45,46]. For the diagnosis of OCI, the findings mentioned above should be kept in mind. However, the differential diagnosis for other diseases, such as ankylosing spondylitis (AS), renal osteodystrophy, lymphoma, metastatic bone disease, Paget's disease, and primary hyperparathyroidism, should also be considered [44].

The mechanical stress hypothesis is widely accepted as explaining the pathogenesis of OCI in pregnancy: "During pregnancy there is a rise in intra-abdominal pressure by the gravid uterus with resultant compression over the $a b$ dominal aorta causing impaired blood circulation in the auricular part of the ilium" [47]. Gillespie and Lloyd-Roberts [43] also suggested obliterative endarteritis in a pregnant woman could result in impaired blood supply to the ilium in OCI. However both hypotheses can't explain why the disorder may be seen in men and nulliparous women, where the infection theory of Szabados sounds appropriate: "Spreading of urinary tract organisms through the nutrient artery of the ilial part of SI joint causes ischemic bone change" [48].

Treatment strategies are usually conservative, and may include: NSAIDs, standard oral analgesics, adjuvant analgesics/coanalgesics, physical agents (superficial heating) by a professional physical therapist, and manual therapy [49]. Some patients improve with SI joint intervention via local anesthetics and corticosteroid injections $[49,50]$. In refractory cases, resection of the ilial part of the joint and SI joint arthrodesis could be considered, although some orthopedists believe this option is unnecessary, as the SI joint remains intact in OCI $[41,47,49]$.

Those with SpA, for example AS, report inflammatory LBP with pain referral to the thigh back, which may be confused with sciatica of lumbar spine origin, especially in atypical early cases and in women [6]. AS diagnosis is based on the modified New York classification criteria, alongside 3 clinical features (inflammatory spinal pain, limited chest expansion, and limited spinal movements).
Radiological sacroiliitis is required for a definitive diagnosis. Treatment consists of NSAIDs, conventional (infliximab, adalimumab) and target-specific biologics (tofacitinib). However, manual, therapist-led spinal-mobilising exercises, swimming, and prone lying positions have also been shown to help patients. IA corticosteroid injection in the SI joint may cause temporary pain relief. However, oral steroids and conventional disease-modifying antirheumatic drugs have been found to be ineffective $[51,52]$.

\section{7) Superior cluneal nerve (SCN) disorder}

The SCN is formed by the anastomosis of the dorsal rami of the T11-L4 spinal nerves. Strong and Davila [53] first described the condition in 1957. The main presenting complaint is LBP, but one-third of patients may report leg pain aggravating on standing, walking, bending from the waist, twisting, climbing/descending stairs, and lifting weight(s). However, hip extension somewhat improves the symptoms [54].

Elderly people experiencing a dorsolumbar vertebral fracture, that is complicated with kyphosis, may develop clinical manifestations akin to SCN disorder [53]. Maigne and Maigne [55] demonstrated a variant of SCN, where dorsal spine pain referred to corresponding subutaneous branches of the dorsal rami, at a spinal level(s) anywhere from T11-L4. Kuniya et al. [54] unveiled in a cadaveric study showing that 42 of $109(39 \%)$ medial branches of the SCN passing under the osteo-fibrous tunnel, located between iliac crest and thoraco-lumbar fascia, became entrapped and produced sciatica-like symptoms. Inferiorly along the iliac crest, the SCN anastomoses with the superior branch of the medial cluneal nerve (MCN) (formed by joining sacral 1-3 nerve dorsal rami), could be an explanation why the SCN generates features alike lumbago with sciatica $[54,56]$.

Local injury during bone graft harvesting from the posterior iliac crest could injure the SCN further. The following two maneuvers may raise suspicion of SCN syndrome: (1) maximal tenderness on the posterior superior iliac crest approximately $7 \mathrm{~cm}$ from midline and $4.5 \mathrm{~cm}$ from the posterior superior iliac spine, and (2) palpation of the maximally tender point reproducing the symptoms [55]. Sonographic tracking of the SCN has also been described (Fig. 3) [57].

Analgesics, including adjuvant analgesics and NSAIDs, are used to treat the condition, although they are found ineffective in most cases. IL injection of procaine (a local anesthetic agent) provides transient pain relief, and repeated shots could be required. Approximately $70 \%$ of patients experience at least $50 \%$ pain reduction, based-on visual analogue score of pain, after three repeated injections. In 

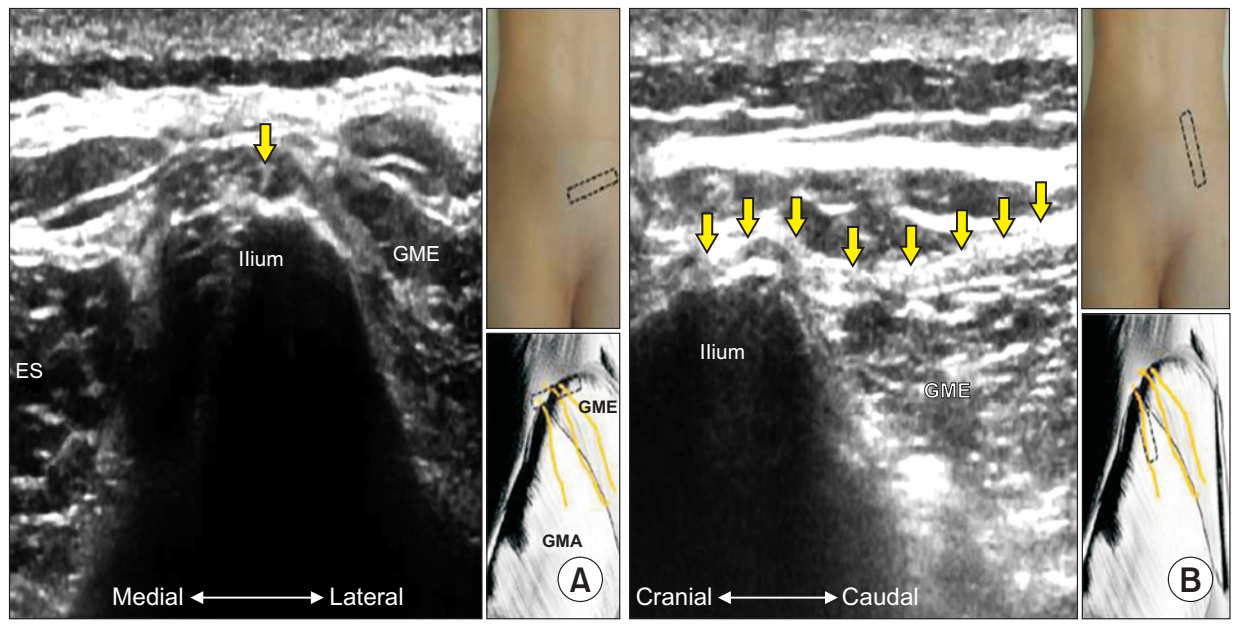

Fig. 3. Ultrasonogram of superior cluneal nerve (SCN). (A) Short axis. (B) Long axis. Yellow arrows indicate SCN. GME: gluteus medius, ES: erector spinae, GMA: gluteus maximus. Adapted from the article of Chang et al. (J Pain Res 2017; 10: 79-88) [57]. refractory and severe cases, SCN release is the ultimate choice, and it was found successful in $100 \%$ of cases, as demonstrated by Morimoto and colleagues $[12,56]$.

\section{8) QL and GME myofascial pain syndromes}

The QL muscle is one of the most frequent sources of myogenic LBP. QL trigger points (TPs) project pain to the SI joint, lower buttock, and lateral hip regions. Sciatica-like pain could be due to satellite TPs in the gluteal muscles, mainly the gluteus medius. Bilateral QL involvement is also possible. To perform a complete examination of the QL muscle, the patient should be positioned lying on his or her side, providing adequate space for palpation between the 12th rib and the iliac crest [58]. Ipsilateral, atrophied paraspinal muscles including the QL, measured under a 3-T MRI scanner, are found on the symptomatic side, in selective cases of patients with acute and chronic LBP [58].

In a cross-sectional study of forty-two patients with nonspecific LBP, TPs were considered active if the subject recognized the local and referred pain. Among patients with non-specific LBP with increased pain intensity and worse sleep quality, active TPs in the QL, iliocostalis lumborum, and gluteus medius muscles were most prevalent [59]. Furthermore, the cross-sectional area of the QL was found to be smaller over the control $(P=0.010)$ in 36 housewives with chronic LBP, as revealed under CT scanning at the L4 spinal level [60]. In another quasi-experimental study, MRI-based QL asymmetry was revealed in male cricketers, predominantly in fast bowlers. Although analgesics provide some relief, a motor control rehabilitation approach was found to be more effective in chronic cases [61].

GME tendinitis could be due to deposition of calcific mass(es) adjacent to the greater trochanter, at the location where the GME tendon inserts; patients present with gluteal pain, pain radiation to the ipsilateral back of the thigh, tenderness around the hip, limited range-of-motion of the hip joint, fever, and raised inflammatory biomarkers [62]. The condition mostly occurs in athletes and subjects who do not regularly exercise, equally affecting men and women. This condition interferes with sleep (side lying) and common weight-bearing tasks [63]. Calcified tissue in GME tendinitis may be found during X-ray, CT, and MRI scanning of the hip/pelvis.

The treatment usually involves analgesia, NSAIDs, extracorporeal shock wave therapy, and IL corticosteroid injections. However, in chronic cases, arthroscopic release of calcified mass(es) may be required [61]. In a case series, Lee and colleagues demonstrated, ultrasound-guided intra-tendinous Platelet-Rich Plasma (PRP) injections could be safe and effective for the treatment of chronic recalcitrant GME tendinitis, due to moderate to severe tendinosis and/or partial tendon tears [64]. A further RCT, involving gluteal tendinopathy, demonstrated significant clinical improvement as measured with the "modified Harris Hip Score", as documented by patients treated with IL-PRP over IL-steroid $(P=0.048)$ at 12 -week follow-up [65].

\section{9) Post-injectional sciatic neuropathy}

SN injury in association with dorso-gluteal site injection has been reported [66]. The degree of injury varies depending upon the specific agent injected, positioning of the needle, and the subcutaneous tissue thickness; widespread axonal and myelin degeneration may be the outcomes of this injury [67]. An injured SN is observed more often in men than in women.

The common peroneal nerve (CPN) component is affected more than the tibial nerve, however, Krasnikova [68] reported that post-injection SN injury can often also be seen in pediatric cases. Mentioned injected materials causing SN neuritis included: NSAIDs, penicillin G, diazepam, and chlorpromazine $[69,70]$. Following injection, there may be a direct needle injury of the SN which later 
becomes inflamed, and potentially fibrosed; alongside chemical induced breakdown in the blood-nerve barrier, direct injury to both axon and Schwann cells occurs [71].

SN injury sequelae range from minor transient sensory disturbance, to severe sensory disturbance, paralysis (foot drop) and foot deformities (equinovarus, calcaneocavus, or equinus deformity) [72-76]. The recommended treatment ranges from a conservative approach to immediate operative exposure, or delayed exploration with neurolysis or resection and anastomosis [71]. Surgical intervention to irrigate injectate and remove hematoma-causisng SN constriction or to release scar tissue constricting the SN should be performed shortly after the nerve injury [77]. Alongside neurolysis, functional reconstruction of the foot and ankle should be performed, when appropriate $[70,73]$.

10) SN tumor (benign and malignant invasion) and vascular malformations

A schwannoma is the most common benign peripheral nerve sheath tumor of the SN. It represents $8 \%$ of all soft tissue tumors involving the $\mathrm{SN}$ [78]. In case of sciatica-like pain with negative lumbar MRI scanning for disc herniation, potential SN schwannoma along its pelvic and extrapelvic courses (near the ischial tuberosity, gluteal region, posterior to the hip joint, and lower thigh) should be investigated [78-80]. Simultaneous presence of neurofibroma and schwannoma compressing the the SN with sciaticalike features, unveiled under MRI/MSUS scanning, has also been reported; surgical excision improves symptoms $[79,81]$.

Schwannomas are solitary, well-circumscribed, encapsulated tumors, originating from spinal nerve roots, or from proximal nerves [79]. Histologically, a schwannoma is composed of spindle-shaped cells arranged in compact fascicular tissue, and smaller cells with ovoid nuclei loosely spaced in a clear watery matrix [79]. In contrast, neurofibromas are often multiple, uncapsulated, and originate from distal nerves, leading to fusiform enlargement of the SN [79].

Sometimes malignant transformation of a benign neurofibroma may occur, depending on the level of different growth factors, and the neural cell adhesion molecules present [82]. Furthermore, giant intra-pelvic malignant peripheral nerve sheath tumor(s) may also be confused with lumbago sciatica [83]. Congenital or acquired arteriovenous malformations (AVM) compressing the SN may mimic sciatica originating from the lumbar spine region [84]. Arteriography and contrast-enhanced CT scanning help with diagnosing AVM; and surgical resection of the AVM and endovascular therapy may provide complete relief. However, rare AVM associated with the SN lacks suf- ficient follow-up [84,85].

11) Extra-pelvic entrapment neuropathy

Entrapment of the lateral cutaneous nerve of the thigh (LCNT), saphenous nerve, sural nerve, and CPN, could present with features mimicking lumbar sciatica [86-92]. LCNT entrapment, also called meralgia paresthetica or Bernhardt-Roth syndrome, is where there is constriction of the nerve under the inguinal ligament at the anterior superior iliac spine. This may lead to pain and reduced sensation over the antero-lateral aspect of the upper thigh. Unilateral involvement is common, and bilateral involvement is also seen, with a predilection to men during their 3rd and 4th decades of life [86].

Being overweight and/or obesity, prone positioning during mechanical ventilation, pregnancy, diabetes mellitus, local trauma, sports injury, lumbar spine surgery, compression injury (rucksack hip belts, pistol belts, parachute harnesses, and body armor), iliac crest bone grafts, appendectomies, and pelvic osteotomies, and Perthes' disease, are common associated risk factors, however it could also be idiopathic $[86,87,89]$. In a US-based study among military servicewomen, higher rates of meralgia paraesthetica were reported than in their male counterparts, with longer load-carriage distance or duration [88].

Alongside clinical examination, nerve conduction velocity (NCV)-EMG, MRI, and CT scanning of the pelvis, as well as MSUS, could help in diagnosing and excluding LCNT mimics $[90,91]$. Histopathological examination of the compressed LCNT revealed axonal demyelination, axonal atrophy, and peri-neural thickening, which are also diagnostic [90].

Conservative treatment, including NSAIDs, tricyclic antidepressants, anticonvulsants, and physical therapy have demonstrated some relief to the patients. MSUS guided IL corticosteroid injection and hydro-dissection of the LCNT also help (Fig. 4) [91]. Pulsed radiofrequency and or surgical excision of the nerve (thus removing the compression element altogether) are required in refractory cases [91,93].

Sural nerve entrapment also mimics PS and PLID [91]. Sural nerve lipoma, schwannoma, and ganglion cyst are common sural nerve entrapment lesions, and successfully excising them result in an improvement of symptoms [94-96]. Sometimes heel straps, ankle/foot compression, repeated ankle sprains, and gastrocnemius muscle injury could contribute to sural nerve constriction [95]. Sural nerve pathology could be tracked under MSUS [97].

Saphenous nerve entrapment with characteristic pain at the medial aspect of leg often may also be confused with lumbar radiculopathy [97]. IL corticosteroid injection around the compression is both diagnostic and therapeu- 


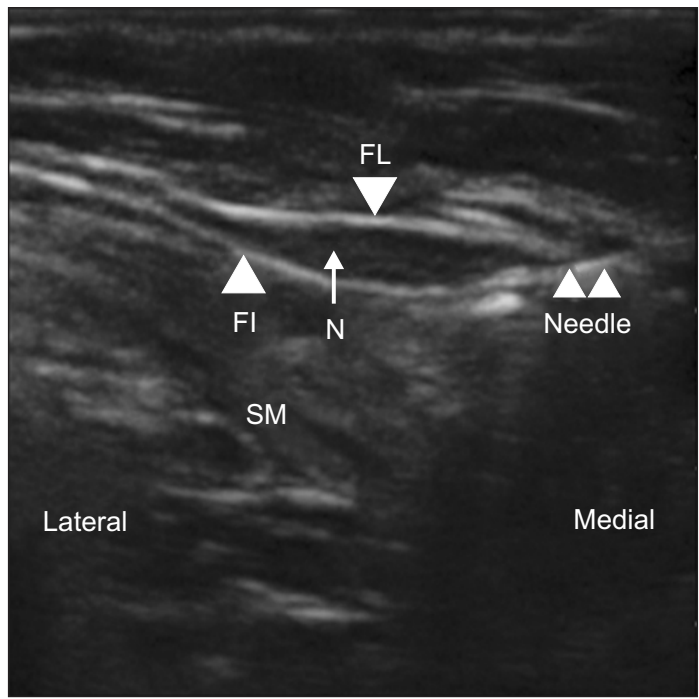

Fig. 4. Short axis ultrasonogram guided injection of lateral cutaneous nerve of thigh (LCNT). FL: fascia lata, Fl: fascia iliaca, N: LCNT, SM: Sartorius muscle. Adapted from the article of Kim et al. (Korean J Pain 2011; 24: 115-8) [91].

tic [97]. Both MRI and MSUS can be useful in diagnosing saphenous nerve compression at various levels; the saphenous nerve commonly becomes compressed at the adductor canal. Also, an enlarged pes anserine bursa may compress the infra-patellar branch of the nerve [97]. Furthermore, $\mathrm{CPN}$ compression at the fibular head may result in sensory and/or motor impairments, including foot drop. Neoplastic lumbosacral plexopathy due to colon cancer, prostate cancer, or gastric cancer, could each initially mimic lumbago with sciatica, thus demanding meticulous laboratory and imaging work-up [98-100].

\section{CONCLUSIONS}

Sciatica can be of spinal and extra-spinal sources, and may, in some cases, be a product of both origins. Sciatica of lumbar spine origin is probably the most common cause of sciatica overall, and is certainly the cause with the most research around it. However, the incidence could potentially be far more frequent for pseudo-sciatica or sciatica mimics; we simply don't know how prevalent extra-spinal sciatica is among the vast number of patients presenting with sciatica. As treatment regimens for spinal and extraspinal sciatica, or sciatica-mimics, are different, their precise definition will help physicians to make a correct diagnosis, and subsequently arrange a treatment plan with a greater chance of targeted success. Hence, further research regarding extra-spinal sciatica, namely addressing prevalence, etiology, risks associations, relation with occupations, disability, sciatica mimics, and sciatic double crush syndrome, could enrich our knowledge and understanding of them, and enhance our ability to create a successful treatment plan.

\section{CONFLICT OF INTEREST}

No potential conflict of interest relevant to this article was reported.

\section{FUNDING}

No funding to declare.

\section{ORCID}

Md Abu Bakar Siddiq, https://orcid.org/0000-0001-9964-599X Danny Clegg, https://orcid.org/0000-0002-0447-5711 Suzon Al Hasan, https://orcid.org/0000-0001-5901-9150 Johannes J Rasker, https://orcid.org/0000-0003-0399-2669

\section{REFERENCES}

1. Stafford MA, Peng P, Hill DA. Sciatica: a review of history, epidemiology, pathogenesis, and the role of epidural steroid injection in management. Br J Anaesth 2007; 99: 46173.

2. Mixter WJ, Barr JS. Rupture of the intervertebral disc with involvement of the spinal canal. N Engl J Med 1934; 211: 210-15.

3. Konstantinou K, Dunn KM, Ogollah R, Vogel S, Hay EM; ATLAS study research team. Characteristics of patients with low back and leg pain seeking treatment in primary care: baseline results from the ATLAS cohort study. BMC Musculoskelet Disord 2015; 16: 332.

4. Ailianou A, Fitsiori A, Syrogiannopoulou A, Toso S, Viallon M, Merlini L, et al. Review of the principal extra spinal pathologies causing sciatica and new MRI approaches. Br J Radiol 2012; 85: 672-81.

5. Valat JP, Genevay S, Marty M, Rozenberg S, Koes B. Sciatica. Best Pract Res Clin Rheumatol 2010; 24: 241-52.

6. Buijs E, Visser L, Groen G. Sciatica and the sacroiliac joint: a forgotten concept. Br J Anaesth 2007; 99: 713-6.

7. Siddiq MA, Hossain MS, Uddin MM, Jahan I, Khasru MR, Haider NM, et al. Piriformis syndrome: a case series of 31 Bangladeshi people with literature review. Eur J Orthop Surg Traumatol 2017; 27: 193-203.

8. Atıcı A, Geler Külcü D, Akpınar P, Akay Urgun D. A rare cause of non-discogenic sciatica; musculus gemellus infe- 
rior: a case report. Turk J Phys Med Rehabil 2017; 63: 355-6.

9. Shete KM, Pandve HT, Joshi T. Adductor magnus tear a rare cause of sciatica: a case report. EC Orthop 2017; 7: 197-201.

10. Panagiotopoulos EC, Syggelos SA, Plotas A, Tsigkas G, Dimopoulos P. Sciatica due to extrapelvic heterotopic ossification: a case report. J Med Case Rep 2008; 2: 298.

11. Hansen JM, Rasti Z, Smith T, Lassen LH. Sciatic neuropathy as first sign of metastasising prostate cancer. BMJ Case Rep 2010; 2010: bcr1220092529.

12. Siddiq AB. Superior cluneal nerve disorder: how often do we consider? J Recent Adv Pain 2016; 2: 4-5.

13. Ergun T, Lakadamyali H. CT and MRI in the evaluation of extraspinal sciatica. Br J Radiol 2010; 83: 791-803.

14. Siddiq MAB, Jahan I, Masihuzzaman S. Wallet neuritis - an example of peripheral sensitization. Curr Rheumatol Rev 2018; 14: 279-83.

15. Critical Appraisals Skills Programme (CASP). CASP checklists [Internet]. Oxford: CASP; 2020. Available at: https:// casp-uk.net/casp-tools-checklists/.

16. Hopayian K, Song F, Riera R, Sambandan S. The clinical features of the piriformis syndrome: a systematic review. Eur Spine J 2010; 19: 2095-109.

17. Robinson DR. Pyriformis syndrome in relation to sciatic pain. Am J Surg 1947; 73: 355-8.

18. Siddiq AB, Rasker JJ. Piriformis syndrome: still unsolved issues. Int J Clin Rheumtol 2018; 13: 338-40.

19. Boyajian-O'Neill LA, McClain RL, Coleman MK, Thomas PP. Diagnosis and management of piriformis syndrome: an osteopathic approach. J Am Osteopath Assoc 2008; 108: 657-64.

20. Siddiq MA, Khasru MR, Rasker JJ. Piriformis syndrome in fibromyalgia: clinical diagnosis and successful treatment. Case Rep Rheumatol 2014; 2014: 893836.

21. Park CH, Lee SH, Lee SC, Park HS. Piriformis muscle: clinical anatomy with computed tomography in Korean population. Korean J Pain 2011; 24: 87-92.

22. Fishman LM, Dombi GW, Michaelsen C, Ringel S, Rozbruch J, Rosner B, et al. Piriformis syndrome: diagnosis, treatment, and outcome--a 10-year study. Arch Phys Med Rehabil 2002; 83: 295-301.

23. Jeong HS, Lee GY, Lee EG, Joe EG, Lee JW, Kang HS. Longterm assessment of clinical outcomes of ultrasound-guided steroid injections in patients with piriformis syndrome. Ultrasonography 2015; 34: 206-10.

24. Al-Al-Shaikh M, Michel F, Parratte B, Kastler B, Vidal C, Aubry S. Évaluation en IRM des modifications morphologiques du muscle piriforme chez les patients traités par toxine botulinique pour syndrome du canal infrapiriforme. J Radiol Diagn Interv 2015; 96 (Suppl 2): S99-105. French.

25. Battle JD. Credit-carditis - a new clinical entity? N Engl J Med 1966; 274: 467.
26. Siddiq MAB. Piriformis syndrome and wallet neuritis: are they the same? Cureus 2018; 10: e2606.

27. Lutz EG. Credit-card-wallet sciatica. JAMA 1978; 240: 738.

28. Bosma JW, Wijntjes J, Hilgevoord TA, Veenstra J. Severe isolated sciatic neuropathy due to a modified lotus position. World J Clin Cases 2014; 2: 39-41.

29. Kim D, Kwon OY, Kim Y, Hye KS, Son S, Park KJ, et al. A case of bilateral sciatic neuropathy caused by lotus position. J Korean Neurol Assoc 2004; 22: 418-20.

30. Siddiq MAB, Rasker JJ. Piriformis pyomyositis, a cause of piriformis syndrome-a systematic search and review. Clin Rheumatol 2019; 38: 1811-21.

31. Nevin Lam AC, Singh SS, Leyland NA. Catamenial sciatica. J Obstet Gynaecol Can 2008; 30: 555.

32. Brosens I, Benagiano G. Endometriosis, a modern syndrome. Indian J Med Res 2011; 133: 581-93.

33. Steinberg JA, Gonda DD, Muller K, Ciacci JD. Endometriosis of the conus medullaris causing cyclic radiculopathy. J Neurosurg Spine 2014; 21: 799-804.

34. Chamié LP, Ribeiro DMFR, Tiferes DA, Macedo Neto AC, Serafini PC. Atypical sites of deeply infiltrative endometriosis: clinical characteristics and imaging findings. Radiographics 2018; 38: 309-28.

35. Vercellini P, Chapron C, Fedele L, Frontino G, Zaina B, Crosignani PG. Evidence for asymmetric distribution of sciatic nerve endometriosis. Obstet Gynecol 2003; 102: 383-7.

36. Dhôte R, Tudoret L, Bachmeyer C, Legmann P, Christoforov B. Cyclic sciatica. A manifestation of compression of the sciatic nerve by endometriosis. A case report. Spine 1996; 21: 2277-9.

37. Possover M, Chiantera V. Isolated infiltrative endometriosis of the sciatic nerve: a report of three patients. Fertil Steril 2007; 87: 417.e17-9.

38. Siquara De Sousa AC, Capek S, Amrami KK, Spinner RJ. Neural involvement in endometriosis: review of anatomic distribution and mechanisms. Clin Anat 2015; 28: 1029-38.

39. Mannan K, Altaf F, Maniar S, Tirabosco R, Sinisi M, Carlstedt T. Cyclical sciatica: endometriosis of the sciatic nerve. J Bone Joint Surg Br 2008; 90: 98-101.

40. Floyd JR 2nd, Keeler ER, Euscher ED, McCutcheon IE. Cyclic sciatica from extrapelvic endometriosis affecting the sciatic nerve. J Neurosurg Spine 2011; 14: 281-9.

41. Ayoub MA. Refractory osteitis condensans ilii: outcome of a novel mini-invasive surgical approach. Int Orthop 2013; 37: 1251-6.

42. Kim HR, Kim YB, Kim DL, Kim SK, Lee SH. A case of osteitis condensans ilii in a nulliparous woman. J Korean Rheum Assoc 2006; 13: 226-9.

43. Gillespie HW, Lloyd-Roberts G. Osteitis condensans. Br J Radiol 1953; 26: 16-21.

44. Vadivelu R, Green TP, Bhatt R. An uncommon cause of back pain in pregnancy. Postgrad Med J 2005; 81: 65-7. 
45. Olivieri I, Gemignani G, Camerini E, Semeria R, Christou C, Giustarini S, et al. Differential diagnosis between osteitis condensans ilii and sacroiliitis. J Rheumatol 1990; 17: 150412.

46. Dihlmann W. Osteitis condensans ilii and sacroiliitis. J Rheumatol 1991; 18: 1430-2.

47. Biswas S, Konala VM, Adapa S, Amudala P, Naramala S. Osteitis condensans ilii: an uncommon cause of back pain. Cureus 2019; 11: e4518.

48. Szabados MC. Osteitis condensans ilit; report of three cases associated with urinary infection. J Fla Med Assoc 1947; 34: 95-9.

49. Mitra R. Osteitis condensans ilii. Rheumatol Int 2010; 30: 293-6.

50. Parperis K, Psarelis S, Nikiphorou E. Osteitis condensans ilii: current knowledge and diagnostic approach. Rheumatol Int 2020; 40: 1013-9.

51. McVeigh CM, Cairns AP. Diagnosis and management of ankylosing spondylitis. BMJ 2006; 333: 581-5.

52. van der Heijde D, Deodhar A, Wei JC, Drescher E, Fleishaker D, Hendrikx T, et al. Tofacitinib in patients with ankylosing spondylitis: a phase II, 16-week, randomised, placebocontrolled, dose-ranging study. Ann Rheum Dis 2017; 76: 1340-7.

53. Strong EK, Davila JC. The cluneal nerve syndrome; a distinct type of low back pain. Ind Med Surg 1957; 26: 417-29.

54. Kuniya H, Aota Y, Saito T, Kamiya Y, Funakoshi K, Terayama $\mathrm{H}$, et al. Anatomical study of superior cluneal nerve entrapment. J Neurosurg Spine 2013; 19: 76-80.

55. Maigne JY, Maigne R. Trigger point of the posterior iliac crest: painful iliolumbar ligament insertion or cutaneous dorsal ramus pain? An anatomic study. Arch Phys Med Rehabil 1991; 72: 734-7.

56. Morimoto D, Isu T, Kim K, Imai T, Yamazaki K, Matsumoto $\mathrm{R}$, et al. Surgical treatment of superior cluneal nerve entrapment neuropathy. J Neurosurg Spine 2013; 19: 71-5.

57. Chang KV, Lin CP, Lin CS, Wu WT, Karmakar MK, Özçakar L. Sonographic tracking of trunk nerves: essential for ultrasound-guided pain management and research. J Pain Res 2017; 10: 79-88.

58. Wan Q, Lin C, Li X, Zeng W, Ma C. MRI assessment of paraspinal muscles in patients with acute and chronic unilateral low back pain. Br J Radiol 2015; 88: 20140546.

59. Iglesias-González JJ, Muñoz-García MT, Rodrigues-deSouza DP, Alburquerque-Sendín F, Fernández-de-LasPeñas C. Myofascial trigger points, pain, disability, and sleep quality in patients with chronic nonspecific low back pain. Pain Med 2013; 14: 1964-70.

60. Kamaz M, Kireşi D, Oğuz H, Emlik D, Levendoğlu F. CT measurement of trunk muscle areas in patients with chronic low back pain. Diagn Interv Radiol 2007; 13: 144-8.

61. Hides J, Stanton W, Freke M, Wilson S, McMahon S, Rich- ardson C. MRI study of the size, symmetry and function of the trunk muscles among elite cricketers with and without low back pain. Br J Sports Med 2009; 43: 310-1.

62. Almedghio S, Garneti N. The acute and chronic presentation of gluteus medius calcific tendinitis- a case report of two. J Orthop Case Rep 2014; 4: 48-50.

63. Grimaldi A, Mellor R, Hodges P, Bennell K, Wajswelner H, Vicenzino B. Gluteal tendinopathy: a review of mechanisms, assessment and management. Sports Med 2015; 45: 1107-19.

64. Lee JJ, Harrison JR, Boachie-Adjei K, Vargas E, Moley PJ. Platelet-rich plasma injections with needle tenotomy for gluteus medius tendinopathy: a registry study with prospective follow-up. Orthop J Sports Med 2016; 4: 2325967116671692.

65. Fitzpatrick J, Bulsara MK, O’Donnell J, McCrory PR, Zheng MH. The effectiveness of platelet-rich plasma injections in gluteal tendinopathy: a randomized, double-blind controlled trial comparing a single platelet-rich plasma injection with a single corticosteroid injection. Am J Sports Med 2018; 46: 933-9.

66. Small SP. Preventing sciatic nerve injury from intramuscular injections: literature review. J Adv Nurs 2004; 47: 287-96.

67. Gentili F, Hudson AR, Hunter D. Clinical and experimental aspects of injection injuries of peripheral nerves. Can J Neurol Sci 1980; 7: 143-51.

68. Krasnikova EIa. [Post-injection neuritis of the sciatic nerve]. Zh Nevropatol Psikhiatr Im S S Korsakova 1986; 86: 499-501. Russian.

69. Geyik S, Geyik M, Yigiter R, Kuzudisli S, Saglam S, Elci MA, et al. Preventing sciatic nerve injury due to intramuscular injection: ten-year single-center experience and literature review. Turk Neurosurg 2017; 27: 636-40.

70. Yaffe B, Pri-Chen S, Lin E, Engel J, Modan M. Peripheral nerve injection injury: an experimental pilot study of treatment modalities. J Reconstr Microsurg 1986; 3: 33-7.

71. Villarejo FJ, Pascual AM. Injection injury of the sciatic nerve (370 cases). Childs Nerv Syst 1993; 9: 229-32.

72. Fatunde OJ, Familusi JB. Injection-induced sciatic nerve injury in Nigerian children. Cent Afr J Med 2001; 47: 35-8.

73. Mayer M, Romain O. [Sciatic paralysis after a buttock intramuscular injection in children: an ongoing risk factor]. Arch Pediatr 2001; 8: 321-3. French.

74. Sobel E, Huang EY, Wieting CB. Drop foot as a complication of acupuncture injury and intragluteal injection. J Am Podiatr Med Assoc 1997; 87: 52-9.

75. Napiontek M, Ruszkowski K. Paralytic drop foot and gluteal fibrosis after intramuscular injections. J Bone Joint Surg Br 1993; 75: 83-5.

76. Bigos SJ, Coleman SS. Foot deformities secondary to gluteal injection in infancy. J Pediatr Orthop 1984; 4: 560-3.

77. Huang Y, Yan Q, Lei W. [Gluteal sciatic nerve injury and 
its treatment]. Zhongguo Xiu Fu Chong Jian Wai Ke Za Zhi 2000; 14: 83-6. Chinese.

78. Godkin O, Ellanti P, O'Toole G. Large schwannoma of the sciatic nerve. BMJ Case Rep 2016; 2016: bcr2016217717.

79. Rhanim A, El Zanati R, Mahfoud M, Berrada MS, El Yaacoubi M. A rare cause of chronic sciatic pain: schwannoma of the sciatic nerve. J Clin Orthop Trauma 2013; 4: 89-92.

80. Munakomi S, Shrestha P. Case report: sciatic nerve schwannoma - a rare cause of sciatica. F1000Res 2017; 6: 267.

81. Sintzoff SA Jr, Bank WO, Gevenois PA, Matos C, Noterman J, Flament-Durand J, et al. Simultaneous neurofibroma and schwannoma of the sciatic nerve. AJNR Am J Neuroradiol 1992; 13: 1249-52.

82. Watanabe T, Oda Y, Tamiya S, Masuda K, Tsuneyoshi M. Malignant peripheral nerve sheath tumour arising within neurofibroma. An immunohistochemical analysis in the comparison between benign and malignant components. J Clin Pathol 2001; 54: 631-6.

83. Wang P, Chen C, Xin X, Liu B, Li W, Yin D, et al. Giant intrapelvic malignant peripheral nerve sheath tumor mimicking disc herniation: a case report. Mol Clin Oncol 2016; 5: 653-6.

84. Van Gompel JJ, Griessenauer CJ, Scheithauer BW, Amrami KK, Spinner RJ. Vascular malformations, rare causes of sciatic neuropathy: a case series. Neurosurgery 2010; 67: 113342.

85. Vos LD, Bom EP, Vroegindeweij D, Tielbeek AV. Congenital pelvic arteriovenous malformation: a rare cause of sciatica. Clin Neurol Neurosurg 1995; 97: 229-32.

86. Agarwal N, Mistry JB, Khandge PV, Hansberry DR, Goldstein IM. Meralgia paresthetica after spine surgery on the Jackson table. Clin Spine Surg 2018; 31: 53-7.

87. Weng WC, Wei YC, Huang WY, Chien YY, Peng TI, Wu CL. Risk factor analysis for meralgia paresthetica: a hospitalbased study in Taiwan. J Clin Neurosci 2017; 43: 192-5.

88. Knapik JJ, Reynolds K, Orr R, Pope R. Load carriage-related paresthesias (part 2): meralgia paresthetica. J Spec Oper Med 2017; 17: 94-100.
89. Juhl CS, Ballegaard M, Bestle MH, Tfelt-Hansen P. Meralgia paresthetica after prone positioning ventilation in the intensive care unit. Case Rep Crit Care 2016; 2016: 7263201.

90. Payne RA, Harbaugh K, Specht CS, Rizk E. Correlation of histopathology and clinical symptoms in meralgia paresthetica. Cureus 2017; 9: el789.

91. Kim JE, Lee SG, Kim EJ, Min BW, Ban JS, Lee JH. Ultrasound-guided lateral femoral cutaneous nerve block in meralgia paresthetica. Korean J Pain 2011; 24: 115-8.

92. Murphy BP. Piriformis syndrome mimics sural nerve entrapment. J Am Podiatr Med Assoc 1997; 87: 183-4.

93. Ghai B, Dhiman D, Loganathan S. Extended duration pulsed radiofrequency for the management of refractory meralgia paresthetica: a series of five cases. Korean J Pain 2018; 31: 215-20.

94. Singh H, Voss A, Sathe V. Sural nerve lipoma: an anatomy review. Ann Clin Case Rep 2016; 1: 1195.

95. Bianchi S, Droz L, Lups Deplaine C, Dubois-Ferriere V, Delmi M. Ultrasonography of the sural nerve: normal and pathologic appearances. J Ultrasound Med 2018; 37: 125765.

96. Paraskevas GK, Natsis K, Tzika M, Ioannidis O. Fascial entrapment of the sural nerve and its clinical relevance. Anat Cell Biol 2014; 47: 144-7.

97. Porr J, Chrobak K, Muir B. Entrapment of the saphenous nerve at the adductor canal affecting the infrapatellar branch - a report on two cases. J Can Chiropr Assoc 2013; 57: 341-9.

98. Jo SY, Im SB, Jeong JH, Cha JG. Lumbosacral plexopathy caused by presacral recurrence of colon cancer mimicking degenerative spinal disease: a case report. Korean J Spine 2015; 12: 103-6.

99. Hansen JM, Rasti Z, Smith T, Lassen LH. Sciatic neuropathy as first sign of metastasising prostate cancer. BMJ Case Rep 2010; 2010: bcr1220092529.

100. Ichikawa J, Matsumoto S, Shimoji T, Tanizawa T, Gokita T, Hayakawa $\mathrm{K}$, et al. Intraneural metastasis of gastric carcinoma leads to sciatic nerve palsy. BMC Cancer 2012; 12: 313. 